\title{
Risk assessment of ice dams for water diversion projects based on fuzzy fault trees
}

\author{
Mengkai Liu ${ }^{1} \mathbb{D} \cdot$ Xiaoxia Dong $^{1} \cdot$ Hui Guo $^{2}$
}

Received: 10 November 2020 / Accepted: 10 December 2020 / Published online: 18 January 2021

(c) The Author(s) 2021

\begin{abstract}
Ice dams are among the important risks affecting the operational safety and water conveyance efficiency of water diversion projects in northern China. However, no evaluation indicator system for ice dam risk assessment of water diversion projects has been proposed. Therefore, in this paper, based on the formation mechanism of ice dams, the risk assessment indicator system and the possibility calculation model of ice dams were both proposed for water diversion projects based on the fuzzy fault tree analysis method. The ice dam risk fault tree constructed in this study mainly includes three aspects: ice production, ice transport, and ice submergence conditions. Eighteen basic risk indicators were identified, and 72 minimum cut sets were obtained by using the mountain climb method. Eight risk indicators were determined as the key risk indicators for ice dams, including meteorological conditions, narrowed cross section, sluice incident, erroneous scheduling judgment, ice cover influence, flat bed slope, control structures, and ice flow resistance of piers. Then, the canal from the Fenzhuanghe sluice to the Beijumahe sluice of the Middle Route of the South-to-North Water Diversion Project was taken as the research object. Combined with the expert scoring method, the ice dam risk probability of the canal was determined to be $0.2029 \times 10^{-2}$, which was defined as a level III risk, which is an occasionally occurring risk. The study results can support ice dam risk prevention and canal system operation in winter for water diversion projects.
\end{abstract}

Keywords Middle Route of the South-to-North Water Diversion Project · Ice dam · Risk assessment $\cdot$ Fuzzy fault tree

\section{Introduction}

Ice dams are a phenomenon in which a large number of large ice blocks quickly accumulate in a specific river or canal cross section, resulting in a rapid decrease in the cross-sectional area and a rapid rise in the upstream water level. Oversized ice dams can induce flooding in river canals. The total length of the main canal of the Middle Route of the Southto-North Water Diversion Project (MRSNWDP) is $1432 \mathrm{~km}$. The Danjiangkou Reservoir is used as the water source. MRSNWDP is a super-large-scale inter-basin water transfer project with large flows, long distances and no regulation reservoirs online that provides living, industrial, agricultural, and ecological water use to four provinces, including

Mengkai Liu

mengkailiu@whu.edu.cn

1 School of Management, Wuhan University of Science and Technology, Wuhan 430065, China

2 Changjiang River Scientific Research Institute, Wuhan 430072, China
Beijing, Tianjin, Hebei, and Henan. Since the whole project was brought into operation in 2014, the canal system has been operated under complex ice evolution and conditions in winter as the spatiotemporal distribution of ice cover and ice thickness increase the threat of ice disasters (Wen et al. 2015). In fact, different degrees of ice conditions appear in the canal downstream of the Anyanghe sluice every winter (Li et al. 2017a). Therefore, the operational strategy with decreased flow in the canal system in winter is different from the strategy for other seasons to improve operational safety. However, ice jam dam events have also occurred, which pose a certain threat to the safety of the project (Duan et al. 2016). Therefore, there is a key question regarding how to protect the canal system from ice dam threats.

In the formation mechanism of ice dams, researchers believe that changes in the water level will produce longitudinal cracks near the shore that cause the breakup of the ice cover along the quay wall (Fig. 1), and transverse cracks appear with the disappearance of the restraint effect of the quay wall on the ice cover (Mao et al. 2007). Then, the ice cover breaks into larger ice blocks, which accumulate in the 


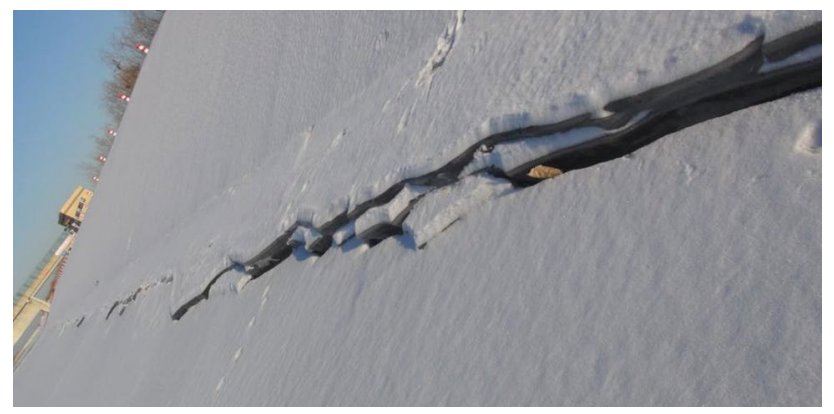

Fig. 1 Longitudinal crack

cross section with the movement of water, and results in a reduction of the amount of water transported downstream and an increase in the upstream water level. Dubé et al. (2014) understood the development processes of ice dams by investigating crystal types and sizes, growth mechanisms, patterns, orientation, and porosity. Ahsan Badhan (2020) experiments were conducted to investigate the formation of ice dams and its evolution in terms of areal extent, average thickness, length, and maximum width under different flow conditions. Li and Lou (2005) studied the types, characteristics, and mechanisms of ice dams. The ice volume, water volume, and boundary conditions of rivers were the main reasons for the formation of ice dams, and it may induce significant backwater effects by increasing wet areas and reducing flow velocity (Stickler et al. 2010). Then, ice dams may fail due to different mechanisms, resulting in flooding (Carling et al. 2010). Zhang et al. (2010) studied the evolution and formation of ice covers, ice jams, and ice dams. The main factors are thermal factors, hydraulic factors, and channel boundary conditions. Munck et al. (2017) constructed models that can quantify various geographical factors to predict where ice dams will occur. Buzin (2010) studied the formation factors of ice dams on rivers and proposed a method for forecasting the duration of ice dam high water levels' stand. A dynamic model of rive ice was established to simulate the dynamic process of ice dam formation and release (Liu et al. 2011). On the basis of analyzing the thermodynamic properties and fracture process of the ice cover, Guo et al. (2011) used numerical simulation and a hydraulic model to determine the river thawing discriminant model and studied how the timing of river thawing was affected by flow rate changes.

Wang et al. (2018) established an experimental model to study the change in hydraulic factors in the process of ice dam breakup, which showed that the water flow velocity increased with increasing ice dam height. Shi and Zhang (2014) established an ice dam solid model to study the conditions of ice dam breakup. The formed ice dam was broken within $2 \mathrm{~h}$ to reduce loss, and multiple solid model experiments of ice dam blasting were performed to determine the optimal explosive charge and position (Yang et al. 2020). On the basis of analyzing the structure of ice dams, a new technique of blasting action under the ice with high safety was proposed (Zhao et al. 2020). Bu et al. (2014) conducted experiments on the automatic breakup of ice dams and obtained index data for blasting and the best location. The formation of ice dams can be controlled by low-frequency modulation of the flow velocity (Lannutti et al. 2020). Liu et al. (2015) studied the ice conditions that may occur during ice flow water transport in the canal system and proposed measures to prevent and control ice hazards based on an analysis of the ice condition production mechanism. A prediction model of ice dam based on river characteristics and neural network theory has been established (Wang et al. 2017; Lindenschmidt et al. 2019; Song et al. 2020). Then, according to the prediction results of river thawing period, risk prevention and control measures were proposed. In general, the evolution, mechanism, cause of formation, prediction, breakup, blasting, prevention and control of ice dams have been studied.

Because the ice dam risk assessment method for a water diversion canal system has not yet been studied completely, an ice dam risk assessment method was proposed by the fuzzy fault tree method. This method included an ice dam risk assessment indicator system, key risk indicator decisions, and the risk level. The method can provide support for the safe operation of water diversion projects in winter.

\section{Research object and basic method}

\section{Research object}

In this paper, the channel between the Fenzhuanghe sluice and the Beijumahe sluice of the MRSNWDP is taken as the research object, as shown in Fig. 2. It is located in Baoding City, with a total length of $25.314 \mathrm{~km}$ and contains two inverted siphons (Nanjumahe inverted siphon, Beijumahe inverted siphon), one aqueduct (Shuibeigou aqueduct), one tunnel (Xiacheting Tunnel), five narrowed cross sections, six bed slope changes, and five channel bends (Liu et al. 2020; Jin et al. 2020). The canal is the last open channel before the MRSNWDP enters Beijing, and it has a longterm average temperature of $-1.5{ }^{\circ} \mathrm{C}$ in winter; ice conditions occur annually. During the winter of 2015-2016, a serious ice jam occurred, and a single pool ice jam with a length of 3.2-7.1 km, due to the ice jam block, reduced the water transport capacity, causing the upstream water level to noticeably rise (Huang et al. 2019). 


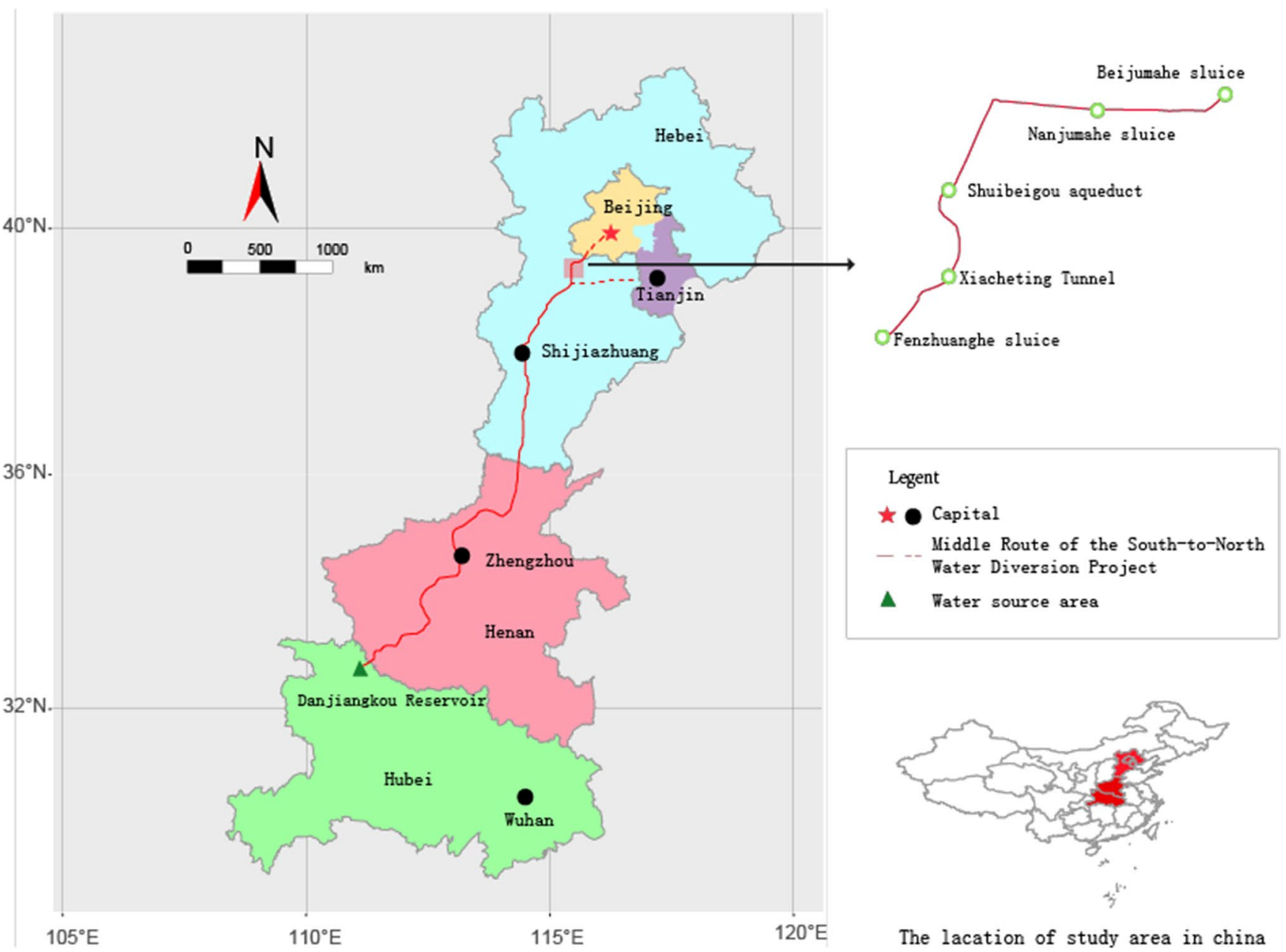

Fig. 2 Location generalization of study area

\section{Basic method}

Fault tree analysis (FTA) is a method that subdivides the causes of system failure factors from top to bottom in a tree diagram according to the event hierarchy ( $\mathrm{Li}$ et al. 2019). The unwanted consequence is regarded as the top event of the fault tree, and the various factors causing the top event are determined as the middle event and bottom event according to the logical relationship between them. Then, all the bottom event factors are qualitatively and quantitatively analyzed, and the key factors causing the system failure are inferred based on the analysis results. Due to the actual situation, the occurrence probability of many events has a certain fuzziness, which is difficult to express by precise probability values; therefore, the fuzzy fault tree analysis (FFTA) method can be used to solve this problem (Shoar et al. 2019). A certain probability interval can be used instead of the precise probability value, the probability of the bottom event is represented by a fuzzy number, and the probability of the occurrence of the top event is calculated by fuzzy mathematical arithmetic (Zhao and Gong 2001). The advantage of this method is that the language used to evaluate events allows errors within a certain range so that a relatively accurate probability of occurrence of the fault tree top events can be obtained (Altabbakh et al. 2013).

The ice dam risk assessment model calculation process is shown in Fig. 3.

\section{Ice dam risk assessment indicator system}

\section{Identification of ice dam risk indicators}

An ice dam is a phenomenon caused by block frazil ice formed by the broken ice cover blocking the water cross section rapidly and largely under the appropriate water flow condition. Therefore, the three main elements of ice dam formation include: (1) ice block production, which is the previous condition for the formation of ice dams; (2) a high flow velocity, which can lead a large block of frazil ice to 
Fig. 3 Ice dam risk assessment model calculation process

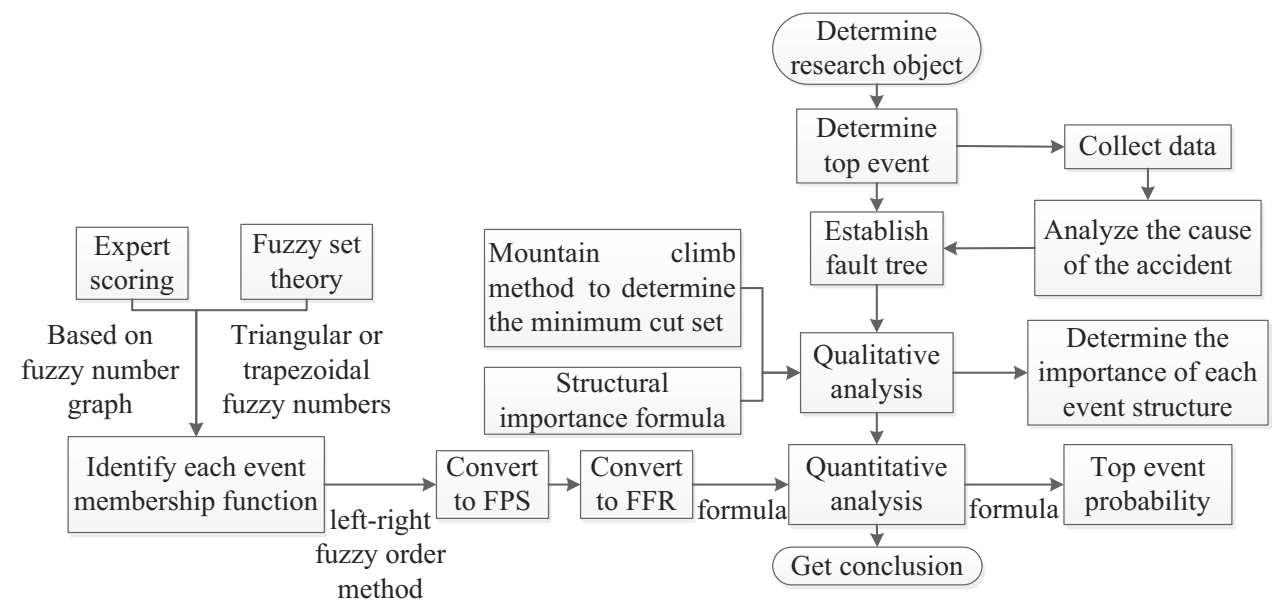

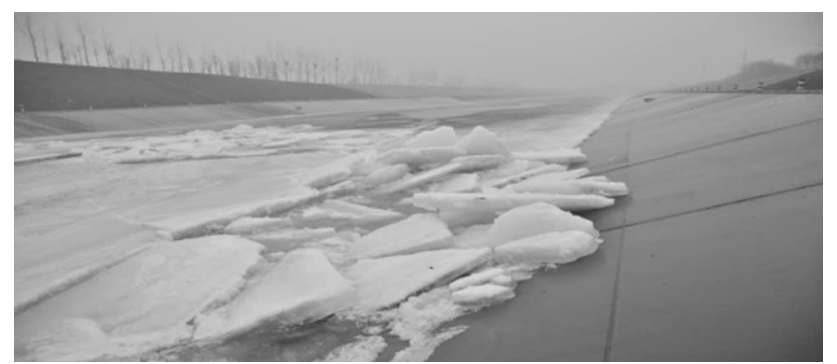

Fig. 4 Ice covers breaking

submerge below the water surface, and ice cover, which provides conditions for blocking the water cross section; and (3) an insufficient ice transport capacity, leading to the formation of an ice dam by the accumulation of a large amount of ice blocks when the ice transport capacity of the cross section is less than that of ice blocks coming from upstream.

\section{Ice block production}

Ice dams mainly occur in the melting period and water transport period under the ice cover; therefore, ice blocks are mainly caused by ice cover breaking and shore ice shedding, and large fluctuations in the water level mainly affect the size and characteristics of ice cover and lead to ice cover breakup, as shown in Fig. 4. The appropriate hydraulic conditions change the geometric size and characteristics of shore ice and lead to shore ice shedding, and the size and characteristics of ice cover and shore ice are affected by meteorological conditions and rising water temperature.

\section{High flow velocity}

Ice block submergence is controlled by the flow velocity, and the critical velocity of submergence is related to the geometric characteristics of ice blocks. From the perspective of a large flow velocity, the reasons for the increase in the flow velocity were mainly considered as follows: large fluctuation in water level, channel structure characteristics, low operating water level, large water transfer of flow, and ice cover influence.

(a) The main reasons for a large fluctuation in the water level are as follows: ice cover changes, channel operation scheduling, canal leakage, and accidents. When ice cover formation occurs, large fluctuations in the water level can occur, so the water velocity may increase greatly. There are two main factors affecting the operation scheduling factors. One is a scheduling system fault, which is manifested as a data acquisition error and sluice fault. A data acquisition error may lead to incorrect operation, causing the channel water level and flow to change significantly. Large fluctuations in the water level can be caused by sluice faults and the normal regulation of the sluice. The other factor is human errors, which show as an incorrect operation and erroneous scheduling judgment. A human error in operation can increase the channel flow, and an erroneous scheduling judgment can make ice blocks accumulate. Canal leakage causes the water level to decrease, the flow to increase and the water level fluctuation to increase.

(b) Channel characteristics indicators include narrowed cross section and steep bed slope changes. The water velocity may increase at a narrowed cross section under the same water flow, and the flow velocity in a channel section with a steep bed slope may be larger, which may cause ice blocks to submerge easily.

(c) Low operating water level. The cause of the a lower operating water level is a low water level control target before the sluice, canal leakage, and operation scheduling process. 
(d) Large water transfer of flow. The main causes of a large water transfer of flow are as follows: operation scheduling factors, high precipitation, water transfer plan with a higher flow, and canal leakage.

(e) Ice cover influence. Downstream ice cover can result in an increase in the hydraulic gradient.

\section{Insufficient ice transport capacity}

Frazil ice in channel sections with an insufficient ice transport capacity is easily submerged and accumulates to form ice dams, while the ice transport capacity is affected by

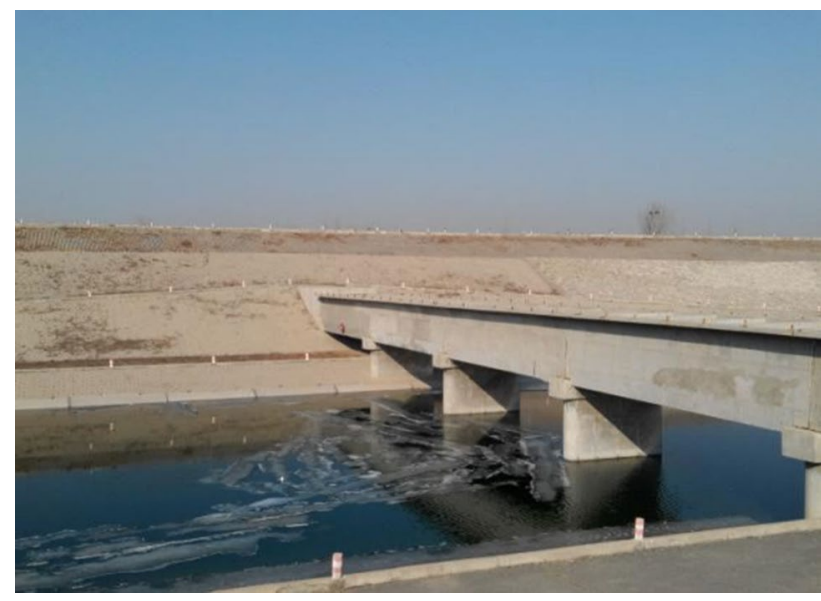

Fig. 5 Pier intercepts ice offshore the channel structure characteristics, ice cover influence and canal system operational mode. Both the ice cover and narrowed cross section reduce the ice transport capacity by reducing the area of passage. The channel structure has a section expansion and flat bed slope, which reduce the water flow velocity, resulting in a decrease in the ice transport capacity, and the blocking of water control structures and piers also reduces the ice transport capacity of the channel, as shown in Fig. 5. When this project is operated under the control mode of a constant water level at the front of downstream sluices, the upstream velocity is higher than the downstream velocity in the channel, so the ice transport capacity downstream is lower than that upstream, but the downstream ice concentration is usually higher than that upstream. Finally, in a cross section with a high frazil ice concentration, the ice transport capacity is insufficient, providing favorable conditions for ice dam formation.

\section{Ice dam risk fault tree}

With 'ice dam' as the top event, the causes of ice block production, high flow velocity and insufficient ice transport capacity are determined by a layer-by-layer analysis, and the fault tree of the ice dam is constructed, as shown in Fig. 6. In the figure, $T$ is the top event, $B_{1}-B_{17}$ is the middle event, and $X_{1}-X_{18}$ is the bottom event. The meanings of each bottom event symbol in the figure are shown in Table 1.

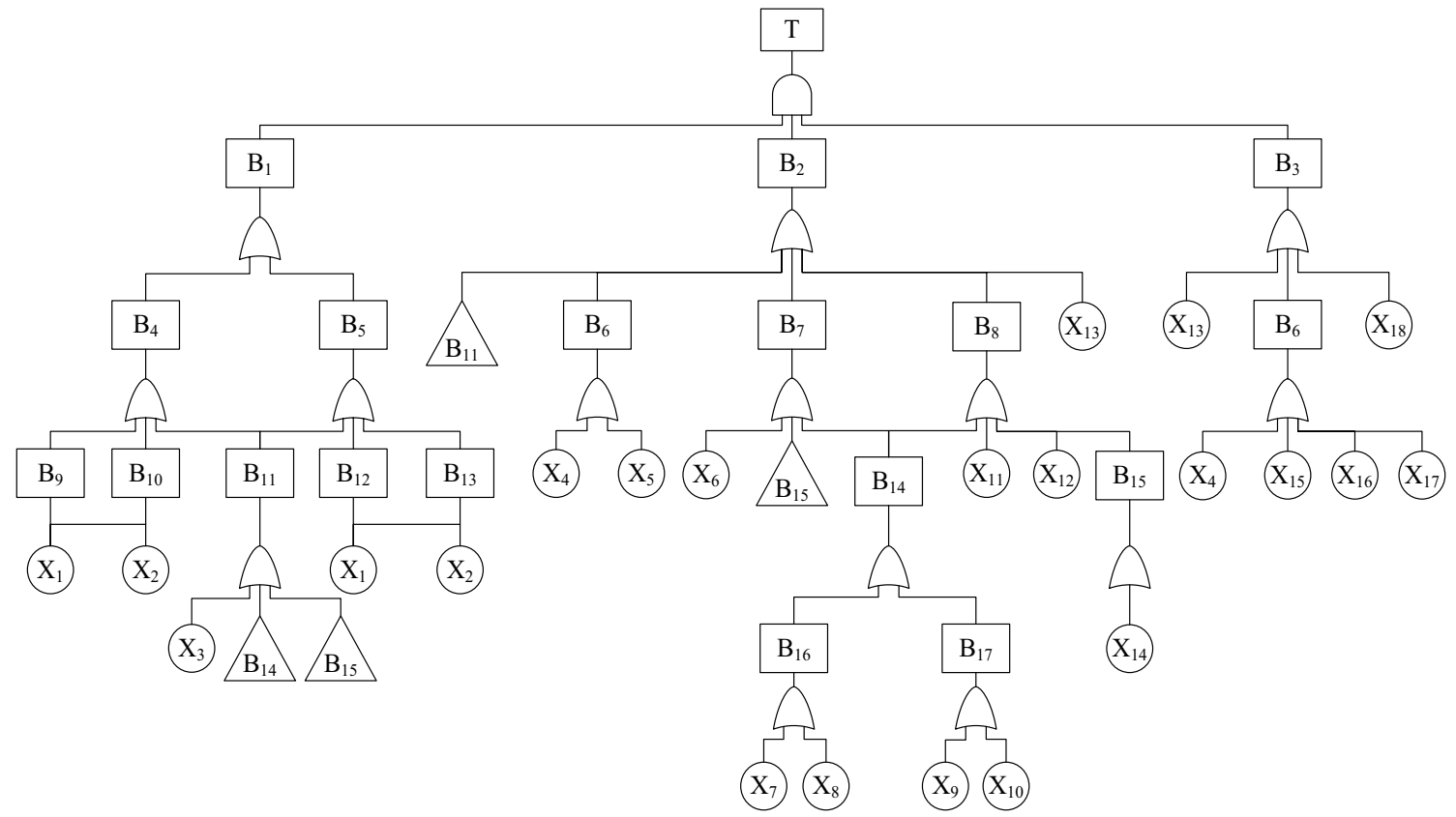

Fig. 6 Fault tree system of ice dams 
Table 1 Symbolic meaning of each bottom event of the ice dam fault tree

\begin{tabular}{llll}
\hline Symbol & Meaning & Symbol & Meaning \\
\hline$T$ & Ice dam & $X_{1}$ & Meteorological conditions \\
$B_{1}$ & Ice blocks production & $X_{2}$ & Water temperature rise \\
$B_{2}$ & High-velocity flow & $X_{3}$ & Ice cover changes \\
$B_{3}$ & Insufficient ice transport capacity & $X_{4}$ & Narrowed cross section \\
$B_{4}$ & Shore ice shedding & $X_{5}$ & Steep bed slope \\
$B_{5}$ & Ice covers breaking & $X_{6}$ & Low water level target before sluice \\
$B_{6}$ & Channel structure characteristics & $X_{7}$ & Data acquisition error \\
$B_{7}$ & Low operating water level & $X_{8}$ & Sluice incident \\
$B_{8}$ & Large water transfer of flow rate & $X_{9}$ & Incorrect operation \\
$B_{9}$ & Characteristics of shore ice & $X_{10}$ & Erroneous scheduling judgment \\
$B_{10}$ & Size of shore ice & $X_{11}$ & High precipitation \\
$B_{11}$ & Large fluctuation of water level & $X_{12}$ & Water transfer plan with a higher flow rate \\
$B_{12}$ & Size of ice cover & $X_{13}$ & Ice cover influence \\
$B_{13}$ & Characteristics of ice cover & $X_{14}$ & Canal leakage \\
$B_{14}$ & Operation scheduling factors & $X_{15}$ & Flat bed slope \\
$B_{15}$ & Accidents & $X_{16}$ & Control structures \\
$B_{16}$ & Scheduling system fault & $X_{17}$ & Ice flow resistance of piers \\
$B_{17}$ & Human errors & $X_{18}$ & Canal system operational mode \\
\hline
\end{tabular}

\section{Determine the minimum cut set}

According to the ice dam fault tree, the minimum cut set is determined by the mountain climb method (Zhou and Wang 2003), and the fault tree is expanded by layers until only the bottom event is included by Boolean algebra arithmetic. The calculation formula is as follows:

$$
\begin{aligned}
T= & B_{1} B_{2} B_{3}=\left(X_{1}+X_{2}+X_{3}+X_{7}+X_{8}+X_{9}+X_{10}+X_{14}\right) \\
& \left(X_{3}+X_{7}+X_{8}+X_{9}+X_{10}+X_{14}+X_{4}+X_{5}+X_{6}+X_{11}\right. \\
& \left.+X_{12}+X_{13}\right)\left(X_{13}+X_{4}+X_{15}+X_{16}+X_{17}+X_{18}\right) \\
= & X_{3} X_{13}+X_{7} X_{13}+X_{8} X_{13}+X_{9} X_{13}+X_{10} X_{13}+X_{14} X_{13} \\
& +X_{1} X_{13}+X_{2} X_{13}+X_{3} X_{4}+X_{7} X_{4}+X_{8} X_{4}+X_{9} X_{4} \\
& +X_{10} X_{4}+X_{14} X_{4}+X_{1} X_{4}+X_{2} X_{4}+X_{3} X_{15}+X_{7} X_{15} \\
& +X_{8} X_{15}+X_{9} X_{15}+X_{10} X_{15}+X_{14} X_{15}+X_{1} X_{5} X_{15} \\
& +X_{1} X_{6} X_{15}+X_{1} X_{11} X_{15}+X_{1} X_{12} X_{15}+X_{2} X_{5} \\
& X_{15}+X_{2} X_{6} X_{15}+X_{2} X_{11} X_{15}+X_{2} X_{12} X_{15}+X_{3} X_{16} \\
& +X_{7} X_{16}+X_{8} X_{16}+X_{9} X_{16}+X_{10} X_{16}+X_{14} X_{16}+X_{1} X_{5} X_{16} \\
& +X_{1} X_{6} X_{16}+X_{1} X_{11} X_{16}+X_{1} X_{12} X_{16}+X_{2} X_{5} X_{16}+X_{2} X_{6} X_{16} \\
& +X_{2} X_{11} X_{16}+X_{2} X_{12} X_{16}+X_{3} X_{17}+X_{7} X_{17}+X_{8} X_{17} \\
& +X_{9} X_{17}+X_{10} X_{17}+X_{14} X_{17}+X_{1} X_{5} X_{17}+X_{1} X_{6} X_{17} \\
& +X_{1} X_{11} X_{17}+X_{1} X_{12} X_{17}+X_{2} X_{5} X_{17}+X_{2} X_{6} X_{17}+X_{2} X_{11} X_{17} \\
& +X_{2} X_{12} X_{17}+X_{3} X_{18}+X_{7} X_{18}+X_{8} X_{18}+X_{9} X_{18}+X_{10} X_{18} \\
& +X_{14} X_{18}+X_{1} X_{5} X_{18}+X_{1} X_{6} X_{18}+X_{1} X_{11} X_{18}+X_{1} X_{12} X_{18} \\
& +X_{2} X_{5} X_{18}+X_{2} X_{6} X_{18}+X_{2} X_{11} X_{18}+X_{2} X_{12} X_{18}
\end{aligned}
$$

Formula (1) shows that the ice dam failure tree contains 72 minimum cut sets, including 40 s-order minimum cut sets and 32 third-order minimum cut sets. The second-order minimum cut sets show that only two events occurring at the same time can cause ice dams. The third-order minimum cut sets show that only three events occurring at the same time can cause ice dams. The minimum cut set $K_{j}$ according to formula (1) in the order arrangement.

\section{Determine the structural importance of bottom events}

The structural importance coefficient indicates the importance degree of a bottom event in the whole structure of the fault tree, which is expressed by $I_{i}$ :

$I i=\sum_{X i \in K j}\left(2^{n i-1}\right)^{-1}$

where $I_{i}$ is the structural importance of the $i$ th bottom event, $X_{i} \in K_{j}$ indicates that the bottom event $X_{i}$ belongs to the minimum cut set $K_{j}, K_{j}$ is the $j$ th minimum cut set, and $n_{i}$ is the number of bottom events in the minimum cut set where bottom event $X_{i}$ is located.

According to the minimum cut set and formula (2), the structural importance of each bottom event is calculated. Taking $X_{1}$ as an example, the calculation is $I_{1}=\left(2^{2-1}\right)^{-1} \times 2$ $+\left(2^{3-1}\right)^{-1} \times 16=5$. The structural importance of other base events is similarly calculated: 


$$
\begin{aligned}
I_{3} & =I_{7}=I_{8}=I_{9}=I_{10}=I_{14}=3, I_{2}=I_{15}=I_{16} \\
& =I_{17}=I_{18}=5, I_{4}=I_{13}=4, I_{5}=I_{6}=I_{11}=I_{12}=2
\end{aligned}
$$

The order of structural importance is:

$$
\begin{aligned}
I_{1} & =I_{2}=I_{15}=I_{16}=\mathrm{I}_{17}=I_{18}>I_{4}=I_{13}>I_{3} \\
& =I_{7}=I_{8}=I_{9}=I_{10}=I_{14}>I_{5}=I_{6}=I_{11}=I_{12}
\end{aligned}
$$

From the order of structural importance, it can be concluded that the structural importance of $I_{1}, I_{2}, I_{15}, I_{16}, I_{17}$ and $I_{18}$ is relatively high, indicating that top events are susceptible to these events; therefore, it is necessary to increase the prevention and control of these events.

\section{Fuzzy assessment of ice dam risk}

In this section, the risk indicator 'low water level target before sluice' is taken as an example to describe the determination process of the membership function, ambiguity function, fuzzy possibility score and fuzzy failure rate. Similarly, the membership function, ambiguity function, fuzzy possibility score and fuzzy failure rate of the remaining 17 risk indicators can be obtained.

\section{Determine the fuzzy set of judging language for the possibility of bottom events}

The processes of bottom events are fuzzy and uncertain. Experts use \{very low (VL), low (L), medium (M), high (H), very high $(\mathrm{VH})\}$ fuzzy language to indicate the possibility of the same event occurring (Xiao 2004). Then, they use fuzzy sets theory analysis expert language, and proper fuzzy numbers are used instead of expert language (Hu 2004). Taking the 'low water level target before sluice' as an example, it is given the natural language of very low, low, medium, high and very high, which can be expressed by triangular or trapezoidal fuzzy numbers, as shown in Fig. 7 (Zhang et al. 2014).

\section{Obtain the fuzzy probability of the bottom event}

Based on the project characteristics, 20 experts were selected to form a judging panel to score the probability of each bottom event and judge the probability of a 'low water level target before sluice' event. The results are as follows: one expert judgment as 'very low,' ten expert judgments as 'low,' six expert judgments as 'medium,' and three expert judgments as 'high.' According to Fig. 7, the corresponding membership function can be expressed as:

$f_{\mathrm{VL}}(x)= \begin{cases}1 & 0<x \leq 0.1 \\ \frac{0.3-x}{0.3-0.1} & 0.1<x \leq 0.3 \\ 0 & \text { other }\end{cases}$
$f_{\mathrm{L}}(x)= \begin{cases}\frac{x-0.1}{0.3-0.1} & 0.1<x \leq 0.3 \\ 1 & 0.3<x \leq 0.4 \\ \frac{0.5-x}{0.5-0.4} & 0.4<x \leq 0.5\end{cases}$

$f_{\mathrm{M}}(x)= \begin{cases}\frac{x-0.4}{0.5-0.4} & 0.4<x \leq 0.5 \\ \frac{0.6-x}{0.6-0.5} & 0.5<x \leq 0.6 \\ 0 & \text { other }\end{cases}$

$f_{\mathrm{H}}(x)= \begin{cases}\frac{x-0.5}{0.6-0.5} & 0.5<x \leq 0.6 \\ 1 & 0.6<x \leq 0.8 \\ \frac{0.9-x}{0.9-0.8} & 0.8<x \leq 0.9\end{cases}$

\section{Judge the transformation of the natural language into a fuzzy function}

Using the $\lambda$-cut set of the fuzzy set to comprehensively treat the expert natural language to reduce fuzziness (Shi and Wang 1993), this paper takes the equal weight analysis of the experts' opinions, and the $\lambda$-cut set of (3)-(6) can be determined:

$\mathrm{VL}_{\lambda}=\left[\mathrm{vl}_{1}, \mathrm{vl}_{2}\right], \mathrm{vl}_{1}=0, \mathrm{vl}_{2}=0.3-0.2 \lambda ; L_{\lambda}=\left[l_{1}, l_{2}\right]$, $l_{1}=0.1+0.2 \lambda, l_{2}=0.5-0.1 \lambda ; M_{\lambda}=\left[m_{1}, m_{2}\right], m_{1}=0.4+0.1 \lambda$, $m_{2}=0.6-0.1 \lambda ; H_{\lambda}=\left[h_{1}, h_{2}\right], h_{1}=0.5+0.1 \lambda, h_{2}=0.9-0.1 \lambda$, where $\mathrm{vl}_{1}, \mathrm{vl}_{2}, l_{1}, l_{2}, m_{1}, m_{2}, h_{1}$, and $h_{2}$ are the upper-lower limits of the membership function $\lambda$-cut set expressed by mathematical expressions.

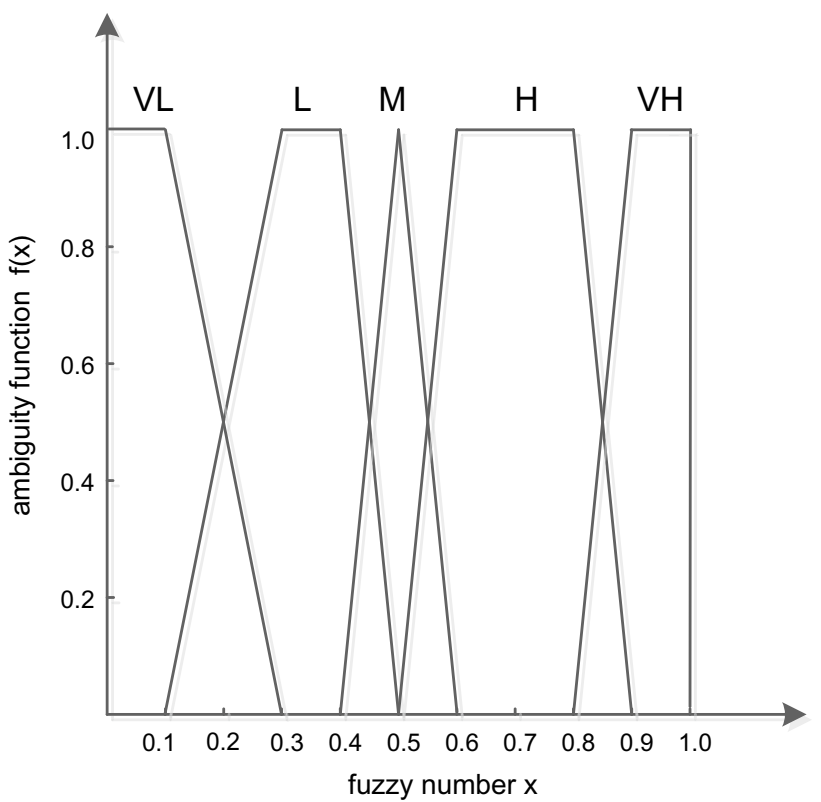

Fig. 7 Fuzzy numbers representing the natural language 
In the $\lambda$-cut set, the total fuzzy set $z$ of the 20 experts is:

$$
\begin{aligned}
f_{1 \mathrm{VL} \oplus 10 \mathrm{~L} \oplus 6 \mathrm{M} \oplus 3 \mathrm{H}}= & \max \mid 1 \otimes f_{\mathrm{VL}}(x) \wedge 10 \otimes f_{\mathrm{L}}(x) \wedge 6 \\
& \otimes f_{\mathrm{M}}(x) \wedge 3 \otimes f_{\mathrm{H}}(x) \mid \\
= & \max \mid 1 \otimes(0)+10 \otimes(0.1+0.2 \lambda) \\
& +6 \otimes(0.4+0.1 \lambda)+3 \otimes(0.5+0.1 \lambda), \\
& 1 \otimes(0.3-0.2 \lambda)+10 \otimes(0.5-0.1 \lambda) \\
& +6 \otimes(0.6-0.1 \lambda)+3 \otimes(0.9-0.1 \lambda) \mid \\
= & |(4.9+2.9 \lambda),(11.6-2.1 \lambda)|
\end{aligned}
$$

According to formula (7), the average fuzzy number $W$ is:

$$
\begin{aligned}
W & =\frac{1}{20}|(4.9+2.9 \lambda),(11.6-2.1 \lambda)| \\
& =|(0.245+0.145 \lambda),(0.58-0.105 \lambda)|
\end{aligned}
$$

Order $W \lambda=|(z 1, z 2)|=|(0.245+0.145 \lambda),(0.58-0.105 \lambda)|$ with $\lambda=z 1-0.245 / 0.145$ and $\lambda=0.58-z 2 / 0.105$, the relation function of the average fuzzy number $W$ is:

$f W(z)= \begin{cases}\frac{z-0.245}{0.145} & 0.245<z \leq 0.39 \\ 1 & 0.39<z \leq 0.475 \\ \frac{0.58-z}{0.105} & 0.475<z \leq 0.58 \\ 0 & \text { other }\end{cases}$

\section{Transform the fuzzy number into the fuzzy probability score}

The fuzzy set is obtained by quantitative evaluation of the natural language, and the fuzzy number is converted into a definite fuzzy possibility score (FPS) for comparative analysis in the fault tree. According to the left-right fuzzy order method proposed by Chen et al. (1992), the fuzzy number can be converted into FPS. The method defines the maximum $f_{\max }(x)$ and minimum $f_{\min }(x)$ fuzzy sets as:

$f_{\max }(x)= \begin{cases}x & (0<x<1) \\ 1 & \text { (other) }\end{cases}$

$f_{\min }(x)= \begin{cases}1-x & (0<x<1) \\ 1 & (\text { other })\end{cases}$

The left-right fuzzy possibility scores $\operatorname{FPS}_{\mathrm{L}}(W)$ and $\operatorname{FPE}_{\mathrm{R}}(W)$ of the average fuzzy number $W$ are:

$\operatorname{FPS}_{\mathrm{L}}(W)=\sup _{x}[f w(x) \wedge f \min (x)]$

$\operatorname{FPS}_{\mathrm{R}}(W)=\sup [f w(x) \wedge f \max (x)]$

The fuzzy possibility score $\operatorname{FPS}_{\mathrm{T}}(W)$ formula is:
$\operatorname{FPS}_{\mathrm{T}}(W)=\frac{\left|\operatorname{FPS}_{\mathrm{R}}(W)+1-\operatorname{FPS}_{\mathrm{L}}(W)\right|}{2}$

According to formula (12), the left-right fuzzy probability scores are $\operatorname{FPS}_{\mathrm{L}}(W)=0.6594, \mathrm{FPS}_{\mathrm{R}}(W)=0.5249$, and FPS $_{\mathrm{T}}(W)=0.43275$.

\section{Transform the FPS into the fuzzy failure rate}

The fuzzy possibility score is converted into the fuzzy failure rate (FFR) according to formula (13) to ensure the consistency of the FPS and FFR (Onisawa 1988):

$$
\begin{aligned}
\mathrm{FFR} & = \begin{cases}\frac{1}{10^{k}} & (\mathrm{FPS} \neq 0) \\
0 & (\mathrm{FPS}=0)\end{cases} \\
& \left(k=2.301 \times\left(\frac{1-F P S}{\mathrm{FPS}}\right)^{\frac{1}{3}}\right)
\end{aligned}
$$

Substituting $\operatorname{FPS}_{\mathrm{T}}(W)=0.43275$ into formula (13), $k=2.518$, that is, FFR $=0.3034 \times 10^{-2}$, $\max$ \{expert scoring is used to analyze the influence of the bottom event on the top event. For example, $X_{5}$ 'steep bed slope' and $X_{15}$ 'flat bed slope' have different influences on the top event due to their different positions and bed slope change ratios. Similarly, the FFR of other bottom events is obtained, as shown in Table 2.

\section{Calculating the probability of minimum cut set}

The probability of the minimum cut set is calculated based on the probability of bottom events. Taking $K_{1}$ as an example, $P\left(K_{1}\right)=X_{3} X_{13}=0.1517 \times 10^{-2} \times 0.7889 \times 10^{-2}=0.1197$ $\times 10^{-4}$. Similarly, the probability of other minimum cut sets can be calculated, as shown in Fig. 8.

According to the analysis of probability, although the probability of $X_{14}$ is less than the probability of $X_{1}$ and $X_{5}$, the probability of $K_{22}=X_{14} X_{15}$ is greater than that of $K_{23}=X_{1} X_{5} X_{15}$, which indicates that the simultaneous

Table 2 FFR of each bottom event of the ice dam fault tree

\begin{tabular}{llll}
\hline Bottom event & $\begin{array}{l}\text { Probability } \\
\text { value } / \times 10^{-2}\end{array}$ & Bottom event & $\begin{array}{l}\text { Probability } \\
\text { value } / \times 10^{-2}\end{array}$ \\
\hline$X_{1}$ & 1.2388 & $X_{10}$ & 1.6406 \\
$X_{2}$ & 0.2518 & $X_{11}$ & 0.0753 \\
$X_{3}$ & 0.1517 & $X_{12}$ & 0.4920 \\
$X_{4}$ & 0.8337 & $X_{13}$ & 0.7889 \\
$X_{5}$ & 0.4498 & $X_{14}$ & 0.0836 \\
$X_{6}$ & 0.3034 & $X_{15}$ & 0.9441 \\
$X_{7}$ & 0.4055 & $X_{16}$ & 1.4859 \\
$X_{8}$ & 0.8375 & $X_{17}$ & 0.8035 \\
$X_{9}$ & 0.3281 & $X_{18}$ & 0.2985 \\
\hline
\end{tabular}




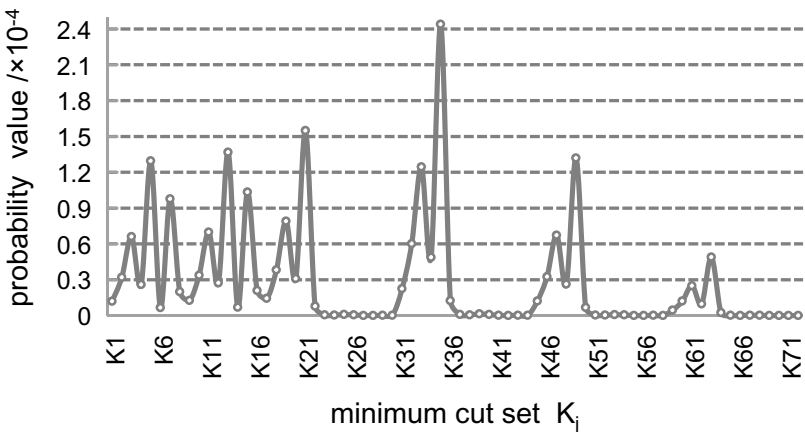

Fig. 8 Probability of the minimum cut set

Table 3 Assessment criterion and level for the probability of an ice dam

\begin{tabular}{lll}
\hline Risk level & Qualitative description & Probability interval \\
\hline I & Impossible occurrence & $<0.0001$ \\
II & Low possibility occurrence & $0.0001-0.001$ \\
III & Occasional occurrence & $0.001-0.01$ \\
IV & Possible occurrence & $0.01-0.1$ \\
V & Often occurrence & $>0.1$ \\
\hline
\end{tabular}

occurrence of events $X_{1}, X_{5}$ and $X_{15}$ will lead to the occurrence of $K_{23}$. Therefore, the probability of $K_{23}$ is small.

\section{Results and discussion}

\section{Risk assessment results and analysis}

The probability of the fuzzy fault tree top event is the sum of the probability of each minimum cut set, and the formula is:

$P(T)=\sum_{j=1}^{n} P(K j)$

where $K_{j}$ is the $j$ numbered minimum cut sets, and $n$ is the total number of minimum cut sets of the fault tree.

Through calculation and analysis, it can be concluded from formula (14) that the probability of the top event of the ice dam failure tree is $P(T)=0.2029 \times 10^{-2}$.

According to the risk occurrence possibility level criterion in GB/T 50927-2013 (2014), the criterion for the probability of an ice dam is shown in Table 3 . The corresponding ice dam level of the project is level III, that is, the level of occasional occurrence. During the winter ice melting period of 2015-2016, a small-volume ice dam approximately $1 \mathrm{~m}$ thick appeared upstream of the inverted siphon of Nanjumahe, which was included in the canal section studied in this paper. Fortunately, the upstream water level was not significantly increased of seriously damaged. Currently, the relevant literature related to the prototype observation of water transfer during the ice period of the MRSNWDP shows that there are sometimes a few ice dam events in the channel studied in this paper, without serious consequences. Therefore, it can be thought that the research method is feasible, the research conclusion is credible, and the model is of generalized application.

\section{Analysis of major risk indicators}

It can be seen from Table 2 that the probability of bottom events distribution ranges $0.07 \times 10^{-2}-1.7 \times 10^{-2}$, the probability of bottom events was sorted by size, and it was found that $0.4 \times 10^{-2}-0.7 \times 10^{-2}$ span is larger. Therefore, bottom events were divided into two categories based on the probability of $0.7 \times 10^{-2}$, and bottom events with a probability greater than $0.7 \times 10^{-2}$ were called as the main risk indicators. Eight main risk indicators were determined, including meteorological conditions, narrowed cross section, sluice incident, erroneous scheduling judgment, ice cover influence, flat bed slope, control structures, and ice flow resistance of piers. The suggestions for risk prevention and control aiming at the main indicators are as follows:

(1) Meteorological conditions are the main thermal factors affecting the formation of ice dams, including air temperature, solar radiation, sunshine time, wind speed and direction and other factors. It is possible to provide data support for the prevention and control of ice condition of water diversion project by improving the winter operation meteorological forecast technology.

(2) Sluice may have internal failure or freeze failure problems, the safety of sluice can be improved and the failure rate of sluice can be reduced through regular overhauling, ice disturbance or artificial de-icing.

(3) Errors scheduling judgment may be caused by data errors, the accuracy of ice regime forecasting can be improved and misjudgment can be reduced by making good detection records of hydraulic parameters, meteorology, water temperature and other relevant variables.

(4) At the narrowed cross section and the flat bed slope, ice blocks are easy to submerge and accumulate, thus providing conditions for the formation of ice dams. The channel size change can be reduced and the risk of ice dam can be reduced by optimizing the narrowed cross section factor and the flat bed slope factor at the design stage.

(5) Ice cover influence is mainly manifested as large hydraulic fluctuations caused by changes in ice cover range and thickness within the canal system. On the one hand, it is easy to cause ice cover to break, which provides a risk source for ice dam formation. On the 
other hand, hydraulic fluctuation easily causes the ice blocks to submerge, which provides the disaster environment for the formation of the ice dam. Therefore, it is necessary to closely observe the changes of ice cover characteristics and strengthen the research on sluice group operation scheduling to reduce the adverse hydraulic response caused by ice cover changes.

(6) Control structures are designed in the form of water flowing but freezing, which is easy to cause a large amount of ice blocks to accumulate in front of the sluice, which is an inevitable phenomenon of water diversion project and an important manifestation different from the river ice problem. At the design stage, the amount of ice resistance can be controlled by reasonably allocating the space between control structures. At the operation stage, the total ice blocks in the canal can be reduced through ice block cable can be installed in front of the control structures, mechanical ice dredging or ice sluice, and thermal melting, so as to control the scale of the ice dam and reduce the risk.

(7) Ice flow resistance of piers is one of the conditions for the formation of the initial ice dam. In the design of water diversion projects, the piers are avoided in the channel section as much as possible.

\section{Analysis of reducing ice dam risk}

According to the controllability of risk indicator, the main risk indicators are divided into controllable risk indicators and non-controllable risk indicators, and controllable risk indicators are divided into controllable at the design stage and controllable at the operation stage. The classification results are shown in Table 4.

From two aspects of the design stage and operation stage of water diversion project, the influence of controllable risk indicators on the risk of ice dam is discussed by reducing the probability of controllable risk indicators to different degrees.

(1) Analysis of the influence of single indicator on ice dam risk

It can be seen from Fig. 9 that:

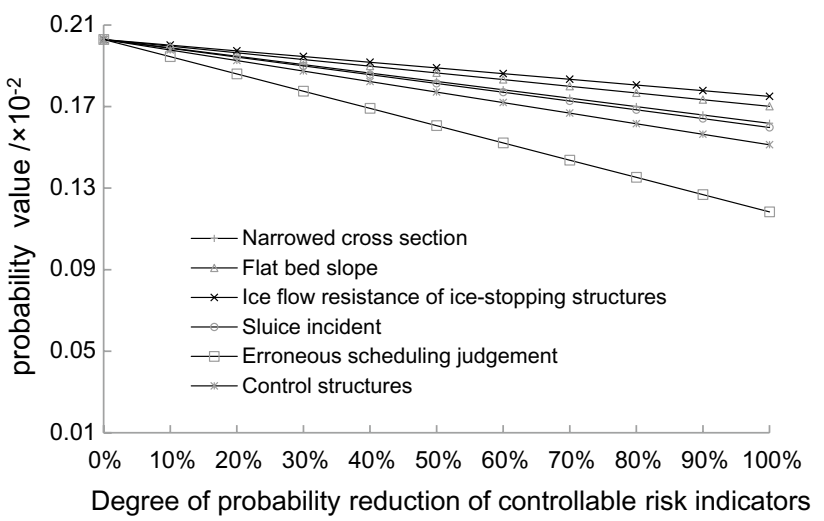

Fig. 9 Influence of single indicator control on ice dam risk

(1) Controlling each indicator can reduce the risk of ice dam, and the degree of risk reduction increases with the degree of control.

(2) Errors scheduling judgment has the best effect on reducing the risk of ice dam, under complete control, the risk probability of ice dam is reduced to $0.118351 \times 10^{-2}$, and the risk is reduced by $41.67 \%$

(3) Under the condition that other risk indicators are completely controlled, the risk reduction degree of ice dam is as follows: control structures can reduce the ice dam risk by $25.45 \%$, sluice incident can reduce the ice dam risk by $21.27 \%$, narrowed cross section can reduce the ice dam risk by $20.28 \%$, flat bed slope can reduce the ice dam risk by $16.17 \%$, and ice flow resistance of piers can reduce the ice dam risk by $13.76 \%$.

(4) All single indicators rank the degree of ice dam risk reduction as follows: errors scheduling judgment $>$ control structures $>$ sluice incident $>$ narrowed cross section $>$ flat bed slope $>$ ice flow resistance of piers.

(2) Analysis of the influence of multi-indicator combination on ice dam risk

It can be seen from Fig. 10 that:

(1) Controlling the controllable indicators at the design stage can effectively reduce the risk of ice
Table 4 Classification of major risk factors

\begin{tabular}{llll}
\hline Controllable risk factors & & Uncontrollable risk factors \\
\hline Controllable at design stage & Controllable at operation stage & \\
\hline Narrowed cross section $X_{4}$ & Sluice incident $X_{8}$ & Meteorological conditions $X_{1}$ \\
Flat bed slope $X_{15}$ & Erroneous scheduling judgment $X_{10}$ & Ice cover influence $X_{13}$ \\
Ice flow resistance of piers $X_{17}$ & Control structures $X_{16}$ & \\
\hline
\end{tabular}


Fig. 10 Influence of multiindicator combined control on ice dam risk

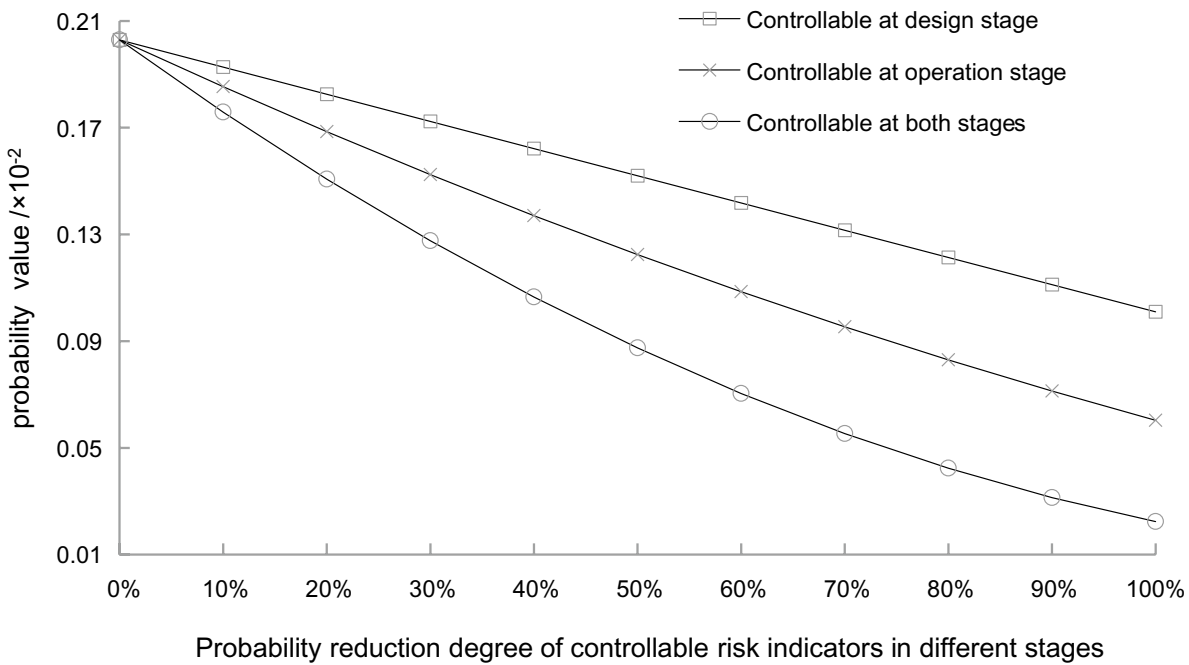

dam, and the reduction effect is significant with the degree of control. Under complete control, the risk probability of ice dam is $0.100992 \times 10^{-2}$, and the risk is reduced by $50.23 \%$.

(2) The risk reduction effect of ice dam is better than that of the design stage when controllable indicators at the operation stage are controlled. When the control degree is $70 \%$, the risk probability of ice dam is $0.095382 \times 10^{-2}$, and the risk level is reduced to level II, which reduces the risk by $52.99 \%$. Under complete control, the risk probability of ice dam is $0.060342 \times 10^{-2}$, and the risk is reduced by $70.26 \%$.

(3) The risk reduction effect of ice dam is the best when controllable indicators at the operation and design stage are controlled. When the control degree is $50 \%$, the risk probability of ice dam is $0.08746 \times 10^{-2}$, and the risk level is reduced to level II, which reduces the risk by $56.89 \%$. Under complete control, the risk probability of ice dam is $0.022384 \times 10^{-2}$, and the risk is reduced by $88.97 \%$.

\section{Analysis of ice dams disaster insurance}

Insurance is a risk transfer tool, which compensates for disaster losses through insurance premium paid and accumulated by the applicant, and an effective non-engineering measure with the functions of pre-disaster prevention, postdisaster compensation and loss reduction ( $\mathrm{Li}$ and $\mathrm{Li} 2012$ ). Excessive ice dams can induce flood, seriously damage the project and the surrounding environment along the line, and cause huge economic losses ( $\mathrm{Li}$ et al. 2017b). Therefore, it is necessary to introduce ice dam disaster insurance to disperse disaster losses.

This insurance is a phased insurance, which ensures the safe operation of water transfer during the ice period of water diversion project. When introducing insurance, it is necessary to determine the insurance rate, premium, insurance coverage, insurance period and insurance amount according to the actual situation of water diversion project, clarify the responsibilities of all parties involved in the insurance, determine the process and method of disaster loss assessment, and formulate the claim standard (Tariq et al. 2014; Kousky and Michel-Kerjan 2017).

\section{Conclusions}

In this study, the safety and pertinence of winter operation risk prevention and control projects are improved by evaluating the ice dam risk of water diversion projects. A fuzzy fault tree-based ice dam risk assessment method for water diversion projects is proposed, and the conclusions are as follows:

(1) From the three aspects of ice production, ice transport, and ice submergence conditions, the risk fault tree of ice dams in water diversion projects was established. Eighteen disaster risk indicators were identified, 72 minimum cut sets were obtained, and eight risk indicators were determined as the main risk indicators, including meteorological conditions, narrowed cross section, sluice incident, erroneous scheduling judgment, ice cover influence, flat bed slope, control structures, and ice flow resistance of piers.

(2) The risk assessment model of ice dams in water diversion projects based on fuzzy fault trees was proposed, and taking part of the main channel of the MRSN- 
WDP as an example, combined with the expert scoring method, the ice dam risk probability of this canal was determined to be $0.2029 \times 10^{-2}$, which is a level III risk, that is, the level of occasional occurrence.

(3) The prevention and control suggestions for ice dams were put forward aiming at the main risk indicators. Controlling each controllable indicator can effectively reduce the risk of ice dams. The risk reduction effect of ice dam was the best when controllable indicators at the operation and design stage were controlled. Under complete control, the risk probability of ice dam was determined to be $0.022384 \times 10^{-2}$, and the risk level was reduced to level II, which reduces the risk by $88.97 \%$.

Funding This study was supported by the National Natural Science Foundation of China (Grant Nos. 51779196, 51309015).

\section{Compliance with ethical standards}

Conflict of interest The authors declare that they have no conflict of interests.

Open Access This article is licensed under a Creative Commons Attribution 4.0 International License, which permits use, sharing, adaptation, distribution and reproduction in any medium or format, as long as you give appropriate credit to the original author(s) and the source, provide a link to the Creative Commons licence, and indicate if changes were made. The images or other third party material in this article are included in the article's Creative Commons licence, unless indicated otherwise in a credit line to the material. If material is not included in the article's Creative Commons licence and your intended use is not permitted by statutory regulation or exceeds the permitted use, you will need to obtain permission directly from the copyright holder. To view a copy of this licence, visit http://creativecommons.org/licenses/by/4.0/.

\section{References}

Ahsan Badhan M (2020) An experimental investigation of hanging ice dam formation. https://hdl.handle.net/1993/34545

Altabbakh H, Murray S, Grantham K, Damle S (2013) Variations in risk management models: a comparative study of the space shuttle challenger disaster. Eng Manag J. https://doi.org/10.1080/10429 247.2013.11431971

Bu XL, Tong Z, Shi XL, Wang HH (2014) Simulation study on blasting of ice dam. Eng Blast 20(03):33-36. https://doi.org/10.3969/j. issn.1006-7051.2014.03.009

Buzin VA (2010) Formation factors and forecast of ice dams on rivers of the north of the European territory of Russia. Russ Meteorol Hydrol 35(4):272-280. https://doi.org/10.3103/S10683739100400 59

Carling P, Villanueva I, Herget J, Wright N, Borodavko P, Morvan $H$ (2010) Unsteady 1D and 2D hydraulic models with ice dam break for quaternary megaflood, Altai Mountains, southern Siberia. Glob Planet Change 70(1-4):24-34. https://doi.org/10.1016/j. gloplacha.2009.11.005

Chen SJ, Wang H, Ching L (1992) Fuzzy multiple attribute decision making: methods and applications. Springer, New York
Duan WG, Hang GB, Yang JB, Liu MK (2016) Ice regime analysis and safe dispatch research on long distance water diversion project in winter. South North Water Transf Water Sci Technol 14(06):96104. https://doi.org/10.13476/j.cnki.nsbdqk.2016.06.017

Dubé M, Turcotte B, Morse B (2014) Inner structure of anchor ice and ice dams in steep channels. Cold Reg Sci Technol 106:194-206. https://doi.org/10.1016/j.coldregions.2014.06.013

GB/T 50927-2013 (2014) Standard of the People's Republic of China, code for risk management of large and medium scale hydropower project

Guo XL, Yang KL, Fu H, Wang T (2011) Numerical simulation of ice regime in the water coqnveyance system during winter in Middle Route of South-to-North Water Transter Project. J Hydraul Eng 42(11):1268-1276. https://doi.org/10.13243/j.cnki. slxb.2011.11.007

Hu BQ (2004) Fuzzy theory basis. Wuhan University Press, Wuhan

Huang GB, Yang JB, Duan WW (2019) Investigation and analysis of ice hazard in operation of typical long distance water transfer project in winter. South North Water Transf Water Sci Technol 17(01):144-149. https://doi.org/10.13476/j.cnki.nsbdq k.2019.0020

Jin SF, Chu JG, Li Y, Wang GL, Yang TT, Leng XY (2020) Dispatch strategies of Beijing-Shijiazhuang section for South-to-North Water Transfer Mid-route Project during winter. South-to-North Water Transfers and Water Science and Technology, pp 1-19. http://kns.cnki.net/kcms/detail/13.1430.TV.20200811.0935.002. html

Kousky C, Michel-Kerjan E (2017) Examining flood insurance claims in the United States: six key findings. J Risk Insur 84(3):819-850. https://doi.org/10.1111/jori.12106

Lannutti E, Lenzano MG, Durand M, Vecchio AL, Moragues S, Lenzano L (2020) Numerical modelling of ice-front oscillations and ice-dam occurrence at Glaciar Perito Moreno, the Southern Patagonia Icefield. Cuade de Investig Geogr 46(1):251-284. https ://doi.org/10.18172/cig.4213

Li XJ, Li JQ (2012) Analysis and inspiration of national flood insurance program in United States. China Water Wastewater 28(15):53-56, 60. https://doi.org/10.3969/j.issn.1000-4602.2012.15.014

Li Y, Lou D (2005) Analysis on the characteristics and causes of ice dam. Heilongjiang Hydraul Sci Technol. https://doi.org/10.14122 /j.cnki.hskj.2005.01.063

Li F, Li Y, Li M, Zhang C (2017a) Spatial distribution of ice hazards in middle route of South-to-North Water Transfer Project based on fuzzy evaluation model. South North Water Transf Water Sci Technol. https://doi.org/10.13476/j.cnki.nsbdqk.2017.01.022

Li CG, Zhang NN, Guo LJ (2017b) Flood insurance: demand, supply and public policy. Insur Stud. https://doi.org/10.13497/j.cnki. is.2015.05.006

Li JW, Qiao JG, Fu X, Liu XL (2019) Failure analysis of the antifloating bolt system based on the fuzzy fault tree. J Saf Environ 19(04):1128-1134. https://doi.org/10.13637/j.i ssn.1009-6094.2019.04.004

Lindenschmidt KE, Rokaya P, Das A, Li Z, Richard D (2019) A novel stochastic modelling approach for operational real-time ice-jam flood forecasting. J Hydrol 575:381-394. https://doi. org/10.1016/j.jhydrol.2019.05.048

Liu DC, Meng WY, Xie W, Ma WL (2011) New ideas of prevention and control of ice jam and ice dam in yellow river. J North China Univ Water Resour Electr Power. https://doi.org/10.19760/j.ncwu. zk.2011.02.001

Liu JJ, Teng LJ, Liu JW (2015) Probable ice cases and methods of ice hazards prevention of China's Middle route South-to-North water transfer project in freezing period. Water Sci Eng Technol. https ://doi.org/10.19733/j.cnki.1672-9900.2015.03.010 
Liu M, Yang J, Guan G (2020) Frazil jam risk assessment for water diversion projects. Water Supply 20(2):428-439. https://doi. org/10.2166/ws.2019.181

Mao ZY, Xu X, Wang AM, Zhang L, Yue GX (2007) Advances in prediction methods for breakup ice-jam. Adv Sci Technol Water Resour. https://doi.org/10.3880/j.issn.1006-7647.2007.03.022

Munck SD, Gauthier Y, Bernier M, Chokmani K, Légaré S (2017) River predisposition to ice jams: a simplified geospatial model. Nat Hazard Earth Sys Sci 17(7):1033-1045. https://doi. org/10.5194/nhess-17-1033-2017

Onisawa T (1988) An approach to human reliability in man-machine systems using error possibility. Fuzzy Set Syst 27(2):87-103. https://doi.org/10.1016/0165-0114(88)90140-6

Shi DH, Wang SR (1993) Fault tree interval analysis theory. Beijing Normal University Publishing House, Beijing

Shi XL, Zhang BS (2014) An experimental investigation on scattering ice dam conditions. China Flood Drought Manag 24(04):17-20. https://doi.org/10.16867/j.cnki.cfdm.2014.04.007

Shoar S, Nasirzadeh F, Zarandi HR (2019) Quantitative assessment of risks on construction projects using fault tree analysis with hybrid uncertainties. Constr Innov 19(1):48-70. https://doi.org/10.1108/ CI-07-2018-0057

Song CS, Zhu XY, Han HW, Lin LB, Yao Z (2020) The influence of riverway characteristics on the generation and dissipation of ice dam in the upper reaches of Heilongjiang River. J Hydraul Eng. https://doi.org/10.13243/j.cnki.slxb.20200045

Stickler M, Alfredsen KT, Linnansaari T, Fjeldstad HP (2010) The influence of dynamic ice formation on hydraulic heterogeneity in steep streams. River Res Appl 26(9):1187-1197. https://doi. org/10.1002/rra.1331

Tariq MA, Hoes OA, Van de Giesen NC (2014) Development of a riskbased framework to integrate flood insurance. J Flood Risk Manag 7(4):291-307. https://doi.org/10.1111/jfr3.12056

Wang T, Liu ZP, Guo XL, Fu H, Liu WB (2017) Prediction of breakup ice jam with artificial neural networks. J Hydraul Eng 48(11):1355-1362. https://doi.org/10.13243/j.cnki.slxb.20170121
Wang PQ, Liu GS, Wang H (2018) Variation characteristics of hydraulic elements in ice dam break. Yellow River 40(12):46-48. https ://doi.org/10.3969/j.issn.1000-1379.2018.12.010

Wen SY, Yang JB, Duan WG, Huang GB (2015) Study on selection of underwater detection equipment of reservoirs and dams using ROV as carrier. Yangtze River. https://doi.org/10.16232/j.c nki.1001-4179.2015.22.023

Xiao CY (2004) Engineering fuzzy system. Science Press, Beijing

Yang KL, Guo XL, Wang T, Guo YX, Peng XM, Wu YN (2020) Theory exploration and practice of preventing ice dam by blasting under ice. J Hydraul Eng. https://doi.org/10.13243/j.cnki. slxb.20190549

Zhang ZZ, Xu JX, Peng SM, Qi QQ, Xue XJ (2010) Analysis on contributing factors of increased ice jam and decreased ice bar at Ning-Mong section of the Yellow River. Yellow River 32(10):3133. https://doi.org/10.3969/j.issn.1000-1379.2010.10.013

Zhang LM, Zhang QY, Wu XG, Cao J, Liu MJ (2014) Risk analysis of shield cutter head failure in metro tunnel construction. China Saf Sci J 24(07):81-87. https://doi.org/10.16265/j.cnki.issn1 003-3033.2014.07.027

Zhao YP, Gong WW (2001) Fuzzy fault tree analysis and its application. China Saf Sci J. https://doi.org/10.16265/j.cnki.issn1 003-3033.2001.06.008

Zhao BY, Liu L, Zhang BS, Shen HD, Ji SY (2020) A river ice dynamic model based on coupling of discrete element method and hydrodynamics. J Hydraul Eng 51(05):617-630. https://doi.org/10.13243 /j.cnki.slxb.20190666

Zhou HJ, Wang SR (2003) Fault tree interval analysis theory. Aviation Industry Press, Beijing

Publisher's note Springer Nature remains neutral with regard to jurisdictional claims in published maps and institutional affiliations. 